\section{Revista}

A Cor

das Letras

\title{
Uma análise lexicológica dos instrumentos e das relações de trabalho em Seara Vermelha, de Jorge Amado
}

\author{
A lexical analysis of tools and working relationships in "Seara vermelha" by Jorge \\ Amado
}

\author{
Maria da Conceição Reios Teixeira* \\ Universidade do Estado da Babia \\ Salvador, Bahia, Brasil
}

\begin{abstract}
Resumo: Em Seara vermelha, Jorge Amado empreende a representação da cultura do povo sertanejo e, por meio de sua narrativa ficcional, faz ecoar marcas identitárias da cultura desse povo. Tal representação só foi possível pelo uso da linguagem. A língua facultou ao homem Jorge Amado estabelecer a relação indivíduo-sociedadeidentidade e cultura. O léxico é o nível da língua que melhor representa o saber de um grupo sócio-linguísticocultural, pois representa a via de acesso para ver e representar o mundo, deixando, portanto, transparecer os valores, as crenças, os hábitos e os costumes de um grupo social do qual o indivíduo faz parte. No presente texto, almejamos apresentar uma leitura da referida obra mediada pelas lentes da lexicologia, especialmente à luz da teoria dos campos lexicais proposta por Coseriu (1986 [1977]). A análise das lexias organizadas em macro e microcampos lexicais dos instrumentos e das relações de trabalho, conforme postula Coseriu, permite fazer a interseção entre o estudo do vocabulário da obra em questão com o conjunto de valores através dos quais se manifestam as relações entre indivíduos de um mesmo grupo que partilham patrimônios comuns como, por exemplo, a cultura, a língua, a religião, os costumes.
\end{abstract}

Palavras-chave: Lexicologia. Campo lexical. Instrumentos de trabalho. Jorge Amado.

\begin{abstract}
The novel Seara Vermelha (AMADO, 1981), pictures a vivid representation of people from Sertão, the arid region of the northeast of Brazil. The language used by the author, mainly the lexical choices gives way for the readers to access the universe of that social group as well as its cultural identity related to tools and working relationships. The support to approach the values, beliefs, and social practices of "sertanejos" through Language comes from Lexicology, specifically the Theory of Lexical Fields as proposed by E. Coseriu (1986 [1977]). Following the perspective of micro and macro lexical fields, the study leads to a broader view of the multiple relationships between the subjects, their environment and the cultural heritage revealed by the fiction of Jorge Amado.
\end{abstract}

Keywords: Lexicology. Lexical field. Working instruments. Jorge Amado.

\section{INTRODUÇÃO}

A língua, além de registrar e acumular as aquisições culturais, espelha a vida do povo, retrata as influências pelas quais passam os grupos humanos, traduzindo as ansiedades que assinalam as diferentes épocas, evidenciando as tendências que marcam cada momento, fornecendo, sempre e em qualquer época, elementos para uma leitura da sociedade.

A organização das experiências do povo que fala uma dada língua dá-se por meio de palavras. Certamente, em função disso, o léxico é considerado por alguns linguistas

* Doutora em Letras e Linguística (UFBA), professora da Universidade do Estado da Bahia. Email: conceicaoreis@terra.com.br. 
como um dos subsistemas da língua mais revestido de dinamicidade, porque, à medida que registra o que há de novo, reflete as transformações pelas quais as comunidades, os grupos sociais passam, ora criando, ora recriando, outras vezes revestindo o sentido já existente de traços semânticos específicos, os quais podem descortinar traços socioculturais de uma determinada comunidade de fala.

Entendendo que é através da palavra que o homem organiza suas experiências, suas aquisições culturais e compartilha todo o seu legado espiritual para os demais membros da comunidade da qual faz parte, acreditamos que, se desejarmos conhecer aspectos culturais de outros períodos da nossa história ou de outros grupos sociais, necessário se faz mergulhar nos textos produzidos (orais ou escritos) e analisar o vocabulário ali empregado. Certamente, desse mergulho, muitas nuances históricoculturais de quem registrou e de seus pares aflorarão e poderão nos oferecer elementos para entendermos a dinâmica social que presidiu no passado e seus reflexos nos dias atuais.

Por essa razão, ultimamente temos nos debruçado sobre alguns textos literários, procedendo ao que chamamos de uma leitura lexicológica, na tentativa de, a partir de escavações arqueológicas, localizando e recolhendo palavras-fósseis, identificar marcas deixadas no texto que possam contribuir de alguma forma para entendermos um pouco mais sobre as culturas, os modos de vida, as práticas sociais dos nossos antepassados. Como todo ato de ler implica, parafraseando Chartier (2001), em uma prática criativa que inventa significados e conteúdos singulares, a nossa leitura lexicológica aqui proposta também procura ser um ato de caçar em propriedade alheia, tecendo, lastreada em nossa própria trajetória de vida e nas teias que nos urdiram enquanto profissional das Letras, uma leitura plausível dentre as várias possíveis do romance Seara vermelha, de Jorge Amado.

$\mathrm{Na}$ leitura da referida obra, recorremos ao auxílio das lentes da semântica estrutural, mormente a teoria dos campos lexicais proposta por Coseriu (1986 [1977]), como elemento mediador do nosso olhar sobre as lexias designativas do sertão nordestino, classificadas como pertencentes ao campo lexical dos instrumentos de trabalho.

Reiterando, a leitura lexicológica aqui apresentada restringe-se à observação do vocabulário coletado na obra Seara vermelha, organizado a partir da teoria dos campos lexicais. Tais lexias, identificadas e classificadas em instrumentos de trabalho para atividades lícitas (enxada, facão, foice, machado, vara, varapau) e instrumentos de trabalho para atividades ilícitas (punhal, fuzil, repetição), perfazem um total de 09 lexias. Essa amostra representa tão somente aquelas postas em funcionamento por Jorge Amado, em 1946, na referida obra, expressando a sua crença ideológica naquele momento.

Cumpre-nos destacar ainda que a teoria dos campos lexicais, elaborada pelo romeno Eugenio Coseriu (1986 [1977]), postula que as lexias agrupadas em um campo são constituídas por uma mesma substância semântica linguisticamente formada, opondo-se por traços mínimos que as diferenciam. Coseriu (1986 [1977]) define campo lexical como sendo o conjunto de palavras que pertencem a uma mesma área de conhecimento e está 
dentro de alguma língua, organizando-se em função de um campo conceitual comum que estabelece entre si relação de significado. Um campo lexical possui subdivisões de subconjuntos variados, conforme a natureza e especificidades dos dados trabalhados.

$\mathrm{Na}$ perspectiva da semântica estrutural, os campos lexicais representam uma estrutura coordenada e hierarquizada com mútua dependência, cuja conceituação encontra-se atrelada e dependente na/da sua estrutura global. Isso significa dizer que a lexia não pode ser analisada individual e isoladamente, porque, fora do conjunto, não existe significação. $\mathrm{O}$ estudo do léxico, consoante à teoria do campo lexical coseriano, permite entrever aspectos do funcionamento da estrutura social da comunidade de fala de uma dada língua.

\section{OS INSTRUMENTOS DE TRABALHO EM SEARA VERMELHA: UMA ANÁLISE LEXICOLÓGICA DAS RELAÇÕES DE TRABALHO}

Em cada época, região, cultura e estágio da história da humanidade, novos instrumentos de trabalho foram criados para que o homem pudesse aperfeiçoar o uso do tempo e da força de trabalho, consequentemente, dinamizando o processo de produção e, inevitavelmente, permitindo a concentração de riquezas nas mãos de alguns.

Os instrumentos de trabalho são os utensílios, máquinas e aparelhos que servem para executar uma atividade, ou seja, são os artefatos de que o homem se serve para exercer efeito no seu objeto de trabalho e ajustá-lo à satisfação das necessidades humanas. O corpo do homem se situa no limite entre natureza e cultura, porque pode, ao mesmo tempo, ser fonte da história e seu produto. E, nessa interação, o homem deparou-se com seus próprios limites corporais, que o levaram a buscar, na natureza, prolongamentos físicos que pudessem aumentar sua capacidade de intervir e de transformar o meio e seus objetos.

Os instrumentos permitiram esse prolongamento do corpo humano. No processo de apropriação humana da natureza, tecnologia natural e tecnologia humana se fundem, fazendo da contínua criação e recriação dos instrumentos de trabalho um capítulo sempre inacabado da história da humanidade. Os instrumentos de trabalho não atuam por si mesmos. Eles são produzidos e significados pelo homem e testemunham as relações deste com a natureza, as formas históricas de vida social e cultural. Os instrumentos são elementos cruciais do processo de hominização. Os primeiros surgiram da própria corporeidade orgânica do homem, de suas mãos, seus braços, de suas pernas e de sua cabeça, tornando-se humanos no processo social do trabalho.

$\mathrm{Na}$ obra em análise, identificamos nove lexias pertencentes ao campo lexical dos instrumentos de trabalho, as quais foram classificadas em instrumentos de trabalho para atividades lícitas (enxada, facão, foice, machado, vara, varapau) e instrumentos de trabalho para atividades ilícitas (punhal, fuzil, repetição).

Em Seara vermelha, as condições de trabalho são precárias, todos os instrumentos utilizados no cultivo da terra são movidos à energia humana, ou seja, dependem única e 
exclusivamente da força despendida dos braços e das pernas do colono, meeiro ou trabalhador. Acreditamos que os instrumentos de trabalho têm dimensão estratégica e revelam a estrutura social dos sujeitos envolvidos, bem como as relações de produção e a condição social de cada sujeito.

A enxada, por exemplo, é o instrumento mais importante e utilizado no grupo social retratado. No seu manuseio, o trabalhador inclina seu tórax para baixo. Obrigatoriamente, a cabeça e o olhar também têm que estar voltados para baixo, para o solo. Durante a execução da tarefa e do movimento de vai e vem dos braços na condução da ferramenta, a mente do operário fica concentrada apenas e exclusivamente na realização daquela atividade, não podendo este desviar seu pensamento para outra coisa ou acontecimento porque poderá ser vítima de acidentes, como, por exemplo, cortar os dedos dos pés ou arrancar algo que não deveria, como uma muda ou planta integrante da cultura agrícola ali praticada e que está a seus cuidados. Além disso, o desvio de atenção do operário interfere diretamente na quantidade e qualidade da sua produção.

Todo trabalhador de atividade lícita, na obra analisada, é remunerado (injustamente) pelo resultado do que produz e é vigiado pelo capataz que lhe impõe longas e árduas jornadas de trabalho. Daí a necessidade de estar muito concentrado, caso contrário, poderá ser punido, pois, no imaginário dos seus comandados, o capataz é a encarnação da figura do diabo: só deseja sugar o sangue alheio, não tem alma, nem coração e nem piedade, só tem o desejo de obter vantagem, produtividade, independente das limitações humanas e temporais. Por vezes, o trabalhador levanta a cabeça, alonga o corpo e põe a enxada debaixo do braço. É nesses raros momentos que pensa em si, em sua família e em sua condição social. Esboça algumas ideias e troca algumas palavras com os companheiros de sua jornada diária, mas, logo em seguida, retoma o vai e vem dos seus braços.

O facão é utilizado normalmente para cortar galhos finos de árvores e arbustos. Em áreas com muitas plantas e/ou matas fechadas tem sempre um trabalhador manejando com grande maestria o facão, limpando-as, para que os demais trabalhadores possam passar livremente, sem que seja atingido por um galho. É um instrumento leve e, quando não está sendo utilizado em alguma atividade laboral, é preso à cintura do trabalhador com o auxílio de uma bainha, espécie de capa.

Durante o seu manuseio, quase sempre, o corpo do trabalhador fica ereto, só é inclinado se o vegetal a ser cortado for pequeno e estiver situado abaixo de sua cintura. $\mathrm{O}$ olhar também deve estar focado no objeto a ser cortado, mas, vez em quando, especialmente quando não estiver concentrado no objeto a ser cortado, volta-se para o horizonte. É nesses momentos que tem oportunidade de pensar em si e em seus problemas, pode esboçar algum anseio, desejo e sonho de uma vida mais digna. Há de se advertir que são pequenos e rápidos lampejos de sonhos em que o trabalhador, em pensamento, projeta-se e almeja realmente uma vida melhor.

No manuseio da foice, o corpo do trabalhador também fica mais ereto e o olhar voltado para o horizonte, quase sempre, na altura do seu corpo. A mente fica concentrada 
no movimento dos braços, no objeto a ser cortado, na força a ser despendida proporcional à espessura do tronco do vegetal a ser cortado. Normalmente, o uso dessa ferramenta requer um grau de concentração e força maior do que os despendidos quando do uso do facão. Aquele que o maneja se exaure com facilidade, dada a energia dispendida na execução da atividade laboral. Por isso, não é qualquer pessoa que está apta a utilizá-la. Apenas homem forte e que se alimenta "bem" manuseia-o. O trabalhador perito na foice recebe remuneração maior que aquele que opera com facão.

O machado, ferramenta usada especialmente para o corte de troncos grossos, requer que o trabalhador imprima muita força física, por isso este se exaure muito mais que aquele que maneja a foice. É um instrumento de trabalho pouco usado, já que, no bioma sertão, a vegetação característica é composta, na sua maioria, de pequenos arbustos. No manuseio, o trabalhador, durante a execução da tarefa, permanece com o corpo inclinado para baixo, erguendo o seu tórax e cabeça por alguns instantes apenas para respirar, recuperar por alguns momentos as forças, pois, em seguida, tem que reiniciar o corte em movimento frenético e fatigante.

Vara e varapau são ferramentas muito rudimentares. São pedaços de madeira extraídos da natureza, não sofreram nenhum tipo de transformação. $\mathrm{Na}$ obra em análise, os sertanejos pouco os usaram porque chuvas e enchentes são raras. $O$ trabalhador manuseia-os com as mãos, com o corpo ereto, poucas vezes é necessário curvar o tórax.

A enxada, o facão, a foice, o machado, a vara e o varapau são utilizados na realização de atividades consideradas lícitas pelo grupo social retratado no romance. Quase todos os instrumentos de trabalho colocam os sujeitos em posição de submissão, já que, para manuseá-los, o corpo, especialmente a cabeça, tem que estar curvada para baixo. Além disso, na realização das tarefas é exigida muita força física e praticamente não há atividades que exijam uso da mente para reflexão, análise crítica e relação dialógica com seus pares.

Motivado pelo desejo de ampliar os lucros à custa da exploração do trabalhador, as relações de trabalho no sertão, discutidas por Jorge Amado, são análogas ao trabalho escravo. Os sujeitos retratados, a quem era negada a posse dos meios de produção, o controle sobre seu trabalho e sobre os produtos desse trabalho, recebiam como pagamento do salário, quase sempre, produtos in natura e/ou ferramentas, e o débito, consequentemente, ia se avolumando até se tornar impossível de ser quitado. Quando o trabalhador decidia abandonar o emprego, em virtude da crescente insatisfação, era coagido a manter o vínculo, sob o argumento de que ainda possuía dívidas a serem quitadas.

Segundo Sento-Sé (2000), o débito é o principal instrumento da escravização e justifica a violenta repressão contra os trabalhadores. A escravidão retratada em Seara vermelha encontra-se ancorada na situação social dos indivíduos, "obrigados" a produzir sob coação, emanada do poder dos latifundiários, coronéis e fazendeiros, que se apropriavam da totalidade do produto do seu trabalho - realizado de forma manual, de 
maneira árdua, sob o sol escaldante, durante cerca de dez ou doze horas por dia -, sem levar em conta sua autonomia e dignidade como indivíduo e sua condição humana.

Há de se observar ainda que as relações de trabalho no sertão nordestino parecem ser reflexo do sistema produtivo que prevaleceu na agricultura no Brasil por muito tempo. Além de contribuir para a exclusão econômica e social, a concentração fundiária fez com que os grupos excluídos se organizassem. Na obra Seara Vermelha, as condições climáticas adversas e, sobretudo, a relação de trabalho injusta levaram alguns trabalhadores a abandonar a enxada, o facão, a foice e o machado - que os exauriam sugando as últimas forças e a esperança de alcançar uma vida digna e uma relação de trabalho mais justa para se organizarem em bandos, trocando tais ferramentas por outras que exigiam pouco esforço braçal, em contrapartida, demandavam muita perícia e estratégia mental, capazes de inseri-los em outro grupo social: o cangaço.

Jorge Amado nos mostra como nasce a violência no campo. $\mathrm{Na}$ obra em análise, o cangaço é um movimento social nordestino fruto do descontentamento com as desigualdades provenientes principalmente das disparidades econômicas, políticas e culturais que envolviam os grupos e as classes sociais do sertão nordestino. É em um contexto marcado profundamente por desigualdades e exclusão que o cangaceiro, o jagunço e o soldado da vingança, cansados de serem explorados, maltratados, valem-se de outras ferramentas e outras práticas laborais para estabelecer uma relação de trabalho mais justa, mesmo que praticando atividades ilícitas. Daí a necessidade de outras ferramentas: punhal, fuzil, repetição.

Em conformidade com a concepção marxista, o conflito constante e incessante entre classes funciona como motor da história. As mudanças sociais operadas no transcorrer da história são influenciadas pela situação econômica dos atores integrantes de uma sociedade. Dentro dessa dinâmica, as respostas para os fenômenos sociais estão inseridas nos meios materiais dos sujeitos. As diferentes situações materiais constituemse em principal vetor de conflitos entre grupos de indivíduos submetidos às diferentes realidades, moldando-os. Portanto, pode-se afirmar que os modos de produção operados por uma sociedade são determinantes tanto para a constituição da realidade social quanto para a determinação dos rumos que seu desenvolvimento toma. Marx (1982), na sua busca por uma lógica para explicar o desenvolvimento humano ao longo da história, afirma que

O modo de produção da vida material condiciona o processo da vida social, política e espiritual em geral. Não é a consciência do homem que determina o seu ser, mas, pelo contrário, o seu ser social é que determina a sua consciência. (MARX, 1982, p. 82)

Os modos de produção, ou seja, as formas de organização de um grupo social diante das relações de produção de seu meio são reflexos das relações envolvidas no processo de construção e manutenção da estrutura econômica de uma sociedade. Em função da produção de subsistência, o trabalho se insere nessa engrenagem e as consequentes divisões, em função das condições materiais dos indivíduos, fomentam a contínua e incessante luta de classes. 
[...] na produção social da sua própria existência, os homens entram em relações determinadas, indispensáveis, independentes de sua vontade; essas relações de produção correspondem a um grau determinado do desenvolvimento de suas forças produtivas materiais. O conjunto dessas relações constitui a estrutura econômica da sociedade, a base real sob a qual se eleva uma superestrutura jurídica e política [...] (MARX, 1982, p.82-83).

Latifundiário, coronel e fazendeiro designam aqueles sujeitos que detêm a terra, o poder político e econômico no sertão brasileiro. São proprietários de grandes extensões de terra, exploram a força de trabalho, escravizam, maltratam os trabalhadores que dão sua vida em longas e árduas jornadas laborais e que, infelizmente, são remunerados com ínfimos salários que não dão para comprar os alimentos mais básicos e essenciais para a sua sobrevivência. Na relação de trabalho regida pelos latifundiários, coronéis e fazendeiros, desempenha função relevante o capataz. É o administrador da propriedade, responsável pela contratação dos demais operários, estabelece regras duras e severas jornadas de trabalho. Dessa relação de trabalho injusta e desumana, das injustiças sociais e do desprezo do Estado nascem os cangaceiros e os novos messias.

A análise das lexias referentes ao campo lexical dos instrumentos de trabalho em Seara vermelha nos autoriza a afirmar que Jorge Amado, ao engendrar a trama e dilemas vividos pelos sujeitos retratados, busca evidenciar, na sua narrativa, a dinâmica das relações de trabalhos e/ou forças produtivas urdidas conforme os princípios marxistas de conceber as edificações e os meios utilizados no processo de produção. De um lado, têmse os meios de produção e, de outro lado, a força de trabalho. Os meios de produção são recursos produtivos físicos como, por exemplo, as ferramentas, a matéria-prima e o espaço físico, representados na obra em análise pela enxada, facão, foice, machado, punhal, repetição, fuzil, manejados nas lavouras das fazendas. A força de trabalho abrange a força física dos trabalhadores em longas e árduas jornadas de trabalho cultivando a terra e seu conhecimento técnico aplicado quando executam cada atividade laboral.

O processo de trabalho é operado dentro da dinâmica de produção de mais-valia. Os latifundiários, fazendeiros e coronéis - não produtores - detentores dos instrumentos de trabalho e da matéria prima - os meios de produção - organizam todo o processo de trabalho para a produção de mercadorias a serem trocadas. As mercadorias, por sua vez, são produzidas de modo que o tempo de trabalho para sua produção seja suficiente para a reprodução da força de trabalho. As relações de produção são marcadas pela exploração. Os detentores da força de trabalho, os colonos, os trabalhadores, os meeiros, são explorados e, por conseguinte, vítimas das desigualdades sociais decorrentes da dinâmica das relações de trabalho injustas a que são diuturnamente submetidos.

\section{CONSIDERAÇÕES FINAIS}

A análise das lexias referentes ao campo dos instrumentos de trabalho lastreada na teoria dos campos lexicais coseriano revela-nos aspectos do funcionamento da 
estrutura social do grupo representado no romance analisado. Através das figuras 1 e 2, procuramos, esquematicamente, representar a frequência de ocorrência da lexia na obra, bem como sua relevância no grupo social retratado, evidenciando a hierarquia na organização estrutural nas relações de trabalho.

A enxada é a ferramenta mais utilizada pelos sujeitos retratados e, ao mesmo tempo, é a que exige mais energia quando do seu manuseio pelo operário. Por esta razão, figura no topo da pirâmide invertida. O varapau, dentre as lexias aqui arroladas, é a menos frequente tanto no número de ocorrência quanto ao seu uso.

\section{INSTRUMENTOS DE TRABALHO ATIVIDADES LÍCITAS - FREQUÊNCIA DE USO E RELEVÂNCIA}

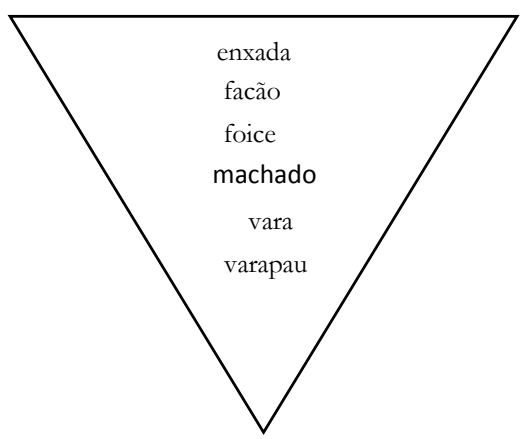

Figura 1: Instrumentos de trabalho para atividades lícitas em Seara vermelha. Fonte: Elaborada pela autora.

Dentre as ferramentas utilizadas para as atividades laborais consideradas na obra em análise como ilícitas, o fuzil é a mais recorrente no romance e utilizada com mais frequência. Daí figurar como a primeira na pirâmide invertida, evidenciado a sua hierarquia no grupo social do cangaço. Na hierarquia de relevância e frequência de uso, punhal figura em última posição.

INSTRUMENTOS DE TRABALHO ATIVIDADES ILÍCITAS - FREQUÊNCIA DE USO E RELEVÂNCIA

Figura 2: Instrumentos de trabalho atividades ilícitas em Seara vermelha.

Fonte: Elaborada pela autora.

A análise permitiu ainda perceber que o manuseio das próprias ferramentas, durante a execução das atividades laborais, é determinante para reforçar ainda mais a 
condição social daqueles que detêm a força de trabalho e, inevitavelmente, alimentam a engrenagem do sistema de produção centrado na exploração da mão de obra, na desigualdade social e na concentração de renda e poder nas mãos dos latifundiários, fazendeiros e coronéis do Nordeste brasileiro.

\section{REFERÊNCIAS}

AMADO, Jorge. Seara vermelha: romance. 37. ed. Rio de Janeiro: Record, 1981.

CHARTIER, Roger. Cultura escrita, literatura e história. Porto Alegre: Artmed, 2001.

COSERIU, Eugenio. Princípios de semântica estructural. Madrid: Gredos, 1977.

MARX, Karl Prefácio. Introdução à Contribuição para a Crítica da Economia Política. Lisboa; Moscovo: Edições Progresso, 1982.

SENTO-SÉ, Jairo Lins de Albuquerque. Trabalho escravo no Brasil na atualidade. São Paulo: 2000.

Recebido em: 02/05/2017

Aprovado em: 08/08/2017

Publicado em: 01/12/2017 